\title{
A winding road to origin discovery
}

\author{
Joyce L. Hamlin • Larry D. Mesner • \\ Pieter A. Dijkwel
}

Published online: 27 October 2009

(C) Springer Science + Business Media B.V. 2009

\begin{abstract}
Studies in our laboratory over the last three decades have shown that the Chinese hamster dihydrofolate reductase (DHFR) origin of replication corresponds to a broad zone of inefficient initiation sites distributed throughout the spacer between the convergently transcribed DHFR and 2BE2121 genes. It is clear from mutational analysis that none of these sites is genetically required for controlling origin activity. However, the integrity of the promoter of the DHFR gene is needed to activate the downstream origin, while the $3^{\prime}$ processing signals prevent invasion and inactivation of the downstream origin by transcription forks. Several other origins in metazoans have been shown to correspond to zones of inefficient sites, while a different subset appears to be similar to the fixed replicators that characterize origins in $S$. cerevisiae and lower organisms. These observations have led us to suggest a model in which the mammalian genome is dotted with a hierarchy of degenerate, redundant, and inefficient replicators at intervals of a kilobase or less, some of which may have evolved to be highly circumscribed and efficient. The activities of initiation sites are proposed to be
\end{abstract}

Responsible Editors: Marie-Nicolle Prioleau and Dean Jackson.

J. L. Hamlin $(\bowtie) \cdot$ L. D. Mesner • P. A. Dijkwel

Department of Biochemistry and Molecular Genetics, University of Virginia School of Medicine,

Charlottesville, VA, USA

e-mail: Jlh2d@virginia.edu largely regulated by local transcription and chromatin architecture. Recently, we and others have devised strategies for identifying active origins on a genomewide scale in order to define their distributions between fixed and dispersive origin types and to detect relationships among origins, genes, and epigenetic markers. The global pictures emerging are suggestive but far from complete and appear to be plagued by some of the same uncertainties that have led to conflicting views of individual origins in the past (particularly DHFR). In this paper, we will trace the history of origin discovery in mammalian genomes, primarily using the well-studied DHFR origin as a model, because it has been analyzed by nearly every available origin mapping technique in several different laboratories, while many origins have been identified by only one. We will address the strengths and shortcomings of the various methods utilized to identify and characterize origins in complex genomes and will point out how we and others were sometimes led astray by false assumptions and biases, as well as insufficient information. The goal is to help guide future experiments that will provide a truly comprehensive and accurate portrait of origins and their regulation. After all, in the words of George Santayana, "Those who do not learn from history are doomed to repeat it."

Key words mammalian replication origins - DHFR . 2-D gels $\cdot$ nascent strands $\cdot$ replication initiation 


\begin{tabular}{|c|c|}
\hline \multicolumn{2}{|c|}{ Abbreviations } \\
\hline $\begin{array}{l}\text { AluI } \\
\text { elements }\end{array}$ & $\begin{array}{l}\text { Repetitive sequence elements that can } \\
\text { be excised from the genome by the } \\
\text { enzyme, } A l u \mathrm{I}\end{array}$ \\
\hline $\begin{array}{l}\text { ARS } \\
\text { element }\end{array}$ & $\begin{array}{l}\text { Autonomously replicating sequence } \\
\text { element }\end{array}$ \\
\hline AT-rich & $\begin{array}{l}\text { Rich in adenosine monophosphate and } \\
\text { thymidine monophosphate }\end{array}$ \\
\hline BND & $\begin{array}{l}\text { Benzoylated naphthoylated DEAE } \\
\text { cellulose }\end{array}$ \\
\hline bp & Base pair \\
\hline BrdU & Bromodeoxyuridine \\
\hline $\mathrm{CHO}$ & Chinese hamster ovary \\
\hline $\begin{array}{l}\text { CpG } \\
\text { islands }\end{array}$ & $\begin{array}{l}\text { Nested stretches of alternating cytidine } \\
\text { and guanidine monophosphates in } \\
\text { complex genomes }\end{array}$ \\
\hline 2-D & Two-dimensional \\
\hline DHFR & Dihydrofolate reductase gene \\
\hline dnaA & $\begin{array}{l}\text { The gene encoding the dnaA initiation } \\
\text { protein from Escherichia coli }\end{array}$ \\
\hline ELF & Early-labeled fragment \\
\hline ENCODE & Encyclopedia of DNA elements \\
\hline $\begin{array}{l}\text { High } \mathrm{C}_{0} \mathrm{t} \\
\text { DNA }\end{array}$ & Repetitive DNA from complex genomes \\
\hline HU & Hydroxyurea \\
\hline $\mathrm{kb}$ & Kilobase pair \\
\hline LIS & Lithium diiodosalicylate \\
\hline M13 & The bacteriophage M13 \\
\hline $\mathrm{nt}$ & Nucleotide \\
\hline OriC and & The origins of replication in the \\
\hline SV40 ori & $\begin{array}{l}\text { Escherichia coli and SV40 viral } \\
\text { chromosomes, respectively }\end{array}$ \\
\hline PCR & Polymerase chain reaction \\
\hline${ }^{32} \mathrm{P}-\mathrm{dCTP}$ & ${ }^{32}$ P-labeled deoxycytidine triphosphate \\
\hline$t_{s}$ & Temperature-sensitive mutation \\
\hline
\end{tabular}

\section{Early models for identifying origins}

The now-classic single-molecule fiber autoradiographic experiments of Huberman and Riggs published in 1968 opened up a new era in the mammalian DNA replication field (Huberman and Riggs 1968). Not only did these studies allow a relatively precise measure of fork rates in mammalian cells, they also established that the majority of origins are bidirectional, are spaced 15-300 kb apart, and sometimes fire coordinately in clusters. It is remarkable that the original interpretations of these data have stood the test of time during the
40 years of subsequent biochemical and genetic investigation into the nature of individual origins in eukaryotic organisms ranging from the simple yeasts to mammals. An important philosophical concept was also introduced by the very nomenclature that Huberman and Riggs utilized to describe initiation sites in mammalian cells: they were termed origins to call attention to the fact that their studies did not say anything about whether initiation was directed by required genetic replicators, as defined by Jacob and Brenner (1963).

The obvious drawback of fiber autoradiography, of course, is the anonymity of any given initiation event identified by grain tracks in an autoradiogram and, thus, the inability to learn about origin sequences or their distributions relative to other genetic markers (although modern versions of this approach have partially corrected this situation; Herrick and Bensimon 2009; Schurra and Bensimon 2009). Thus, the challenge has been to localize individual initiation sites along chromosomes biochemically. Following the experimental pathway that led to the identification of Escherichia coli oriC (Yasuda and Hirota 1977; von Meyenburg et al. 1978) and to autonomously replicating sequence (ARS) elements in S. cerevisiae (Chan and Tye 1980; Stinchcomb et al. 1980), attempts were made early on to rescue "replicators" from mammalian chromosomes by tethering genomic restriction fragments to a selectable marker, transfecting into a suitable host cell, and assaying for high-frequency transformation (Roth et al. 1983; Holst et al. 1988; Krysan et al. 1989; Heinzel et al. 1991). While certain sequences may, in fact, replicate better than others when examined on an individual basis (e.g., Frappier and Zannis-Hadjopoulos 1987; Leffak and James 1989), this approach has not been successful in identifying a comprehensive subset of genomic restriction fragments that contain bona fide replicators. In hindsight, this is probably the consequence of the very large number of potential initiation sites with only modest replicator activity that probably populate any restriction fragment over a certain size (see below).

The inability to isolate ARS elements en masse from complex genomes thus required that origins be identified based on the unique physical properties of replication start sites in the genome (illustrated in Fig. 1). Indeed, this is an example of the complementary approach that led to the identification of oriC (Marsh and Worcel 1977). In these experiments, cells were 
Fig. 1 Origin mapping schemes take advantage of the unique properties of initiation sites. A fixed bidirectional origin is shown along with the sites for a restriction enzyme that places the start site in the middle of fragment $\mathrm{C}$ (red vertical lines) or off-center (blue lines). Within each expanding bubble are shown gray lines indicating nascent leading and small lagging strands on each template. Below are shown the nascent strands that would be released by heating or alkali, along with their RNA primers

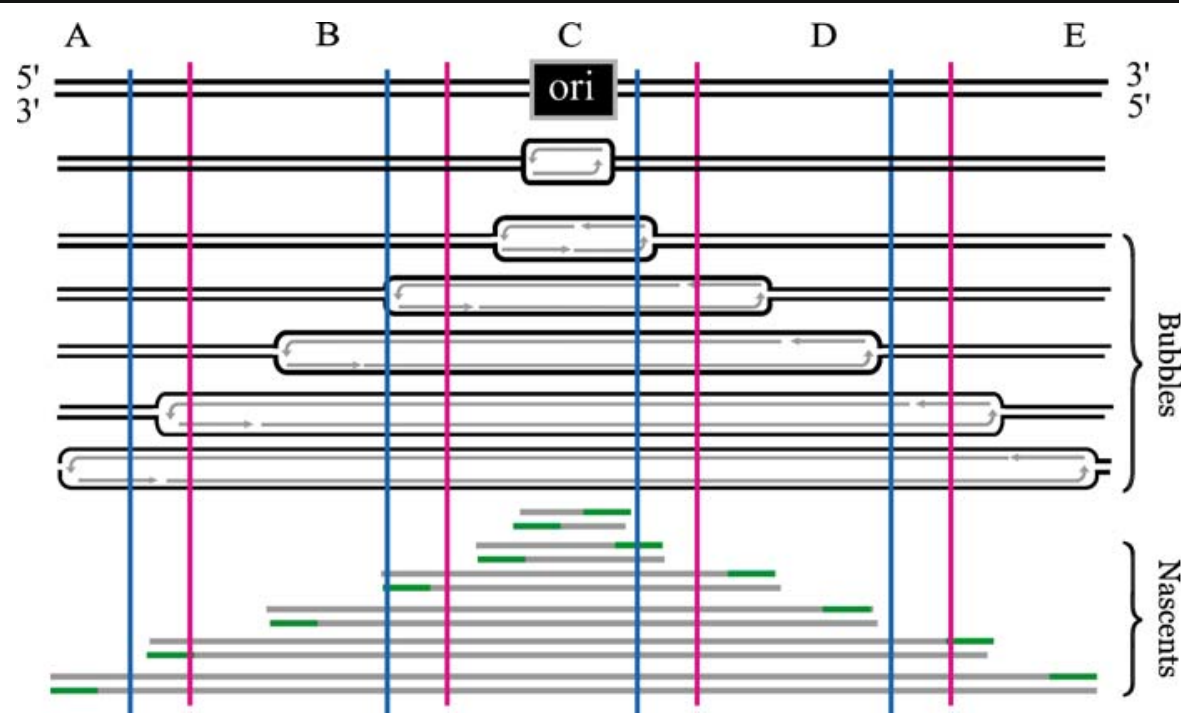

released into $\mathrm{S}$ phase in the presence of ${ }^{3} \mathrm{H}$ thymidine for a few minutes after reversal of a very tight dnaA $t_{s} G_{1} / S$ block. The pattern of HindIII fragment labeling, as well as the knowledge that replication forks were bidirectional (Prescott and Kuempel 1972), led simultaneously to ordering of the fragments and identification of the most highly labeled (earliest-replicating) one. Importantly, this approach does not end up with a physical product as does an ARS assay but rather a location vis-à-vis markers such as genes or restriction sites. Thus, right from the outset, origin-finding schemes for complex genomes largely focused on well-studied regions that had already been mapped and cloned owing to previous interest in the local transcription unit(s).

The problem with using this scheme to identify initiation sites in mammalian genomes, of course, is one of complexity. OriC is the only initiation site in the $E$. coli genome under most circumstances, and its $\sim 4 \times 10^{6}$ bp genome contains only $\sim 10^{3}$ restriction fragments. Hence, a readable pattern could be deduced from the few dozen origin-proximal fragments that were labeled in the first few minutes after release from the dnaA $\mathrm{t}_{\mathrm{s}}$ block. However, the typical diploid mammalian genome probably contains $>5 \times 10^{4}$ start sites distributed among $6 \times 10^{9} \mathrm{bp}$ of sequence. Regardless of the degree of synchrony that might be achieved with mammalian cultured cells, no conceivable labeling strategy could sort out the complex labeling pattern of several thousand origins firing almost simultaneously as a mammalian cell enters $\mathrm{S}$ phase.

\section{Strategies for localizing initiation sites in complex genomes}

In the early 1980 s, our laboratory took advantage of the fortunate congruence of three important features of Chinese hamster cells in order to identify and characterize the first mammalian origin of replication: (1) their ability to be arrested in a non-S-phase condition (i.e., $\mathrm{G}_{0}$ ) in response to isoleucine deprivation (Tobey 1973), thus allowing subsequent collection at the $\mathrm{G}_{1} / \mathrm{S}$ boundary after release from the $\mathrm{G}_{0}$ block into a replication inhibitor (Hamlin and Pardee 1976); (2) their ability to amplify a relatively circumscribed region of the genome (the dihydrofolate reductase (DHFR) domain) in response to increasing concentrations of the competitive inhibitor, methotrexate (Biedler and Spengler 1976); and (3) the availability of several interesting variants developed in other labs that subsequently allowed genetic analysis of elements required to effect initiation in the locus (Urlaub et al. 1986; Jin et al. 1995). We began our origin studies by developing a Chinese hamster ovary $(\mathrm{CHO})$ cell line (CHOC400) that had amplified a $240-\mathrm{kb}$ region encompassing the DHFR gene $\sim 800$ times, with the consequence that the 50 or so restriction fragments within the repeating amplicon could actually be visualized against the background of single-copy fragments in agarose gel separations (Milbrandt et al. 1981). These amplified repeats were analogous to a high copy number plasmid, except that the multiple copies were stably arrayed in tandem in the bodies of chromosomes. 
Identifying early-labeling fragments as cells enter $S$ phase The fact that $\mathrm{CHOC} 400$ cells could be so easily synchronized allowed the selective labeling of the earliest-replicating restriction fragments (ELFs) in the repeating unit by brief release from a $\mathrm{G}_{1} / \mathrm{S}$ aphidicolin or hydroxyurea block into ${ }^{14} \mathrm{C}$-thymidine (Heintz and Hamlin 1982). About a half-dozen bands were identified by this protocol, of which a 6-kb band was the most prominent, followed by an 11-kb fragment. Essentially, the same ELFs were detected when cells were released from a $\mathrm{G}_{0}$ block into medium containing ${ }^{14} \mathrm{C}$-thymidine and the leaky chain terminator, cytosine arabinoside, to stall replication forks very close to initiation sites (Heintz and Hamlin 1983a, b). Thus, we had approximately recapitulated the experiments that mapped oriC to only a few neighboring restriction fragments in the E. coli genome (Marsh and Worcel 1977).

Importantly, these labeling experiments showed for the first time that replication initiates within specific regions of the chromosome. In the pre-epigenetic era, this outcome suggested immediately that initiation might be controlled by genetic replicators, just as it is in the genomes of lower organisms. However, at the time, we lacked a viable phenotypic assay for origin function or even a map of the chromosomal DHFR locus to help position the ELFs. Undaunted, we attempted to identify the region containing the amplified ELFs by excising the 6- and $11-\mathrm{kb}$ bands from the agarose gel, labeling them with ${ }^{32} \mathrm{P}-\mathrm{dCTP}$ and using them to probe a genomic CHOC400 cosmid library that we had just prepared (Heintz et al. 1983). Happily, one cosmid (S21) was recovered that appeared to contain all of the prominent ELFs detected in the in vivo labeling experiment. Within a few years, we had isolated overlapping cosmids representing the entire $240-\mathrm{kb}$ repeating unit and found that all of the ELFs mapped contiguously within the $55-\mathrm{kb}$ spacer between the convergently transcribed DHFR and 2BE2121 genes (Fig. 2; Looney and Hamlin 1987). Thus, we thought we now had the DHFR origin in hand. As we will see, this turned out to be somewhat of an oversimplification. Later, we will also see that there are serious differences between blocking cells prior to S-phase entry with a tight $t_{s}$ initiation mutant (as in E. coli) and collecting them in a somewhat leaky replication inhibitor (such as aphidicolin or hydroxyurea).

[Note that henceforward, we will italicize the important messages that we feel should be considered in designing origin-finding schemes in future.]
The limitation of this in vivo labeling approach was the difficulty of discerning which of the ELFs was labeled most intensely (i.e., first), since the background labeling from thousands of single-copy, early-firing origins precluded quantification of relative specific activities. In addition, subsequent mapping studies showed that there were actually two adjacent $6-\mathrm{kb}$ EcoRI fragments in this region, the most $5^{\prime}$ of which was excluded from cosmid S21 (Fig. 2; Heintz et al. 1983). Therefore, we did not know whether the 6-kb band was the most highly labeled because it represented two adjacent fragments or because one member replicated first and therefore must contain the origin.

To address this problem, an independent study devised a different strategy in which early-replicating DNA was radiolabeled either in vivo or in vitro in the first few minutes of $\mathrm{S}$ phase, and the sheared, labeled DNA was hybridized to a series of similarly sized $X b a \mathrm{I}$ fragments from the intergenic spacer that encompassed the two 6-kb ELFs and a few flanking fragments, but not the region flanking the 11-kb ELF (Burhans et al. 1986). When relative labeling was compared among these fragments, the $X b a \mathrm{I}$ fragment most closely corresponding to the upstream 6-kb ELF (termed R1-F') was the most active. Thus, it was concluded that the origin in this locus was confined to a limited region of the intergenic spacer encompassed by R1-F'. As we will see, later studies proved this conclusion to be essentially incorrect.

In an attempt to quantify the actual in vivo labeling pattern in the intergenic spacer as a whole, we adapted a clever in-gel renaturation technique developed by Roninson (1983) in which a restriction digest of early-labeled DNA was separated on an agarose gel, and the gel was then subjected to multiple cycles of denaturation and renaturation, the latter for a time long enough to allow only amplified sequences to reanneal (Leu and Hamlin 1989). With the background labeling reduced essentially to zero by this procedure, densitometry allowed an estimate of labeling intensities relative to labeled log-phase DNA. Once again, the 6-kb doublet was the most highly labeled, and the 11-kb ELF was only somewhat less so. By digesting the genomic DNA with an enzyme combination (BamH1 and HindIII) that reduced the average fragment length, a much higher-resolution picture of the labeling pattern in the spacer region was obtained, which confirmed the suggestion that the upstream $6-\mathrm{kb}$ fragment $\left(\mathrm{R} 1-\mathrm{F}^{\prime}\right)$ was somewhat more intensely labeled 

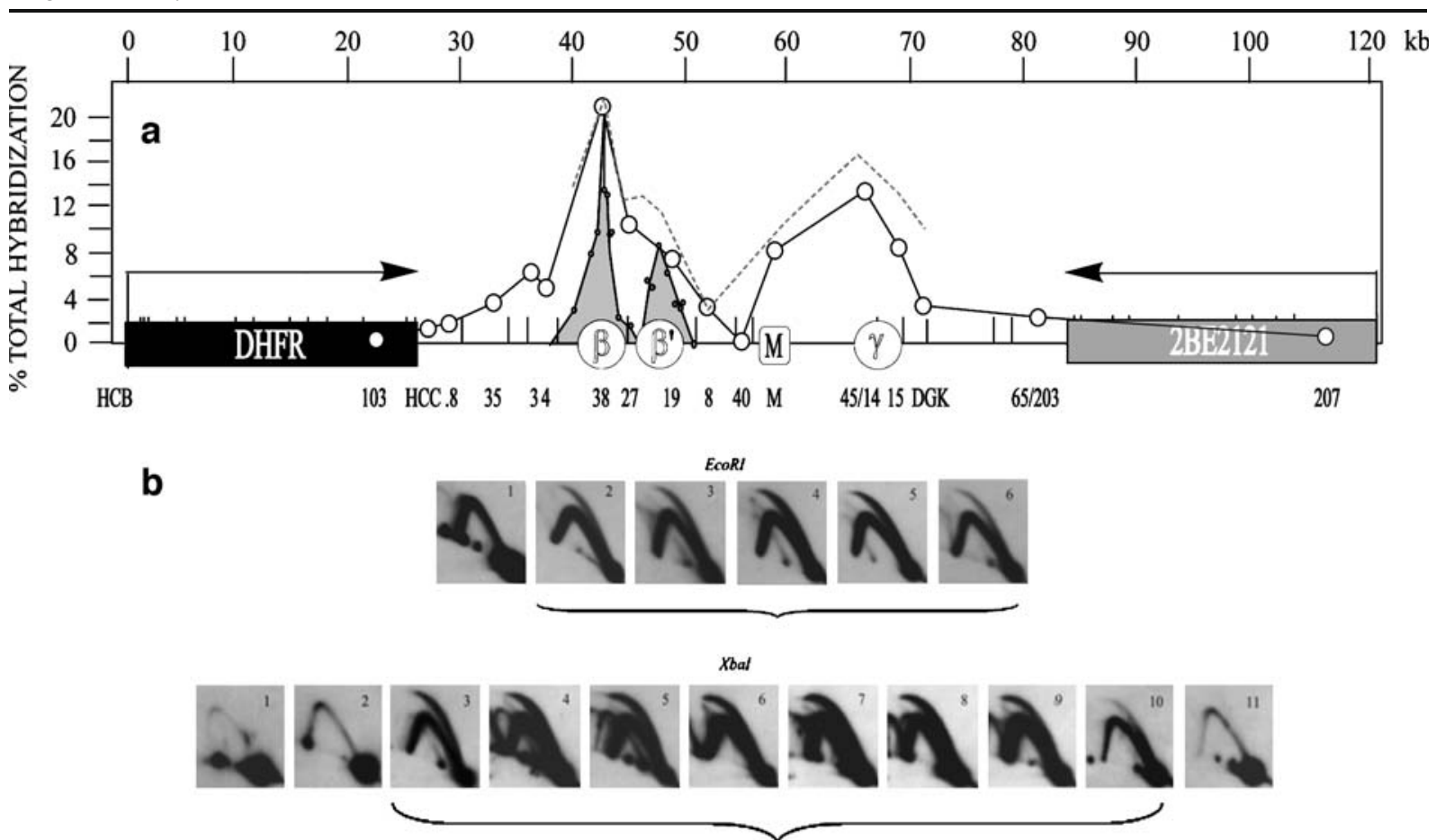

Fig. 2 The DHFR initiation zone. a The central 120-kb core of the 240-kb Chinese hamster DHFR locus is shown, with the three curves representing results from three different origin mapping schemes: (1) the dotted line above is a redrawing of the data from an in-gel denaturation study of ELFs (Leu and Hamlin 1989), (2) the solid black line represents data from an experiment in which ELFs synthesized at the beginning of $\mathrm{S}$ phase were radiolabeled in vitro and hybridized to 22 immobilized clones from across the region, and (3) the filled

than its 6-kb neighbor, R1-F (Burhans et al. 1986). Importantly, however, this analysis clearly showed that the peak at R1-F' was approximately equal to that of the 11-kb ELF lying 22-kb downstream (Fig. 2, dashed curve). The two peaks were named ori- $\beta$ and ori- $\gamma$ (a contemporaneous study on a larger DHFR amplicon in another cell line uncovered an additional origin (ori- $\alpha$ ) about $200 \mathrm{~kb}$ upstream (Ma et al. 1990)).

Unfortunately, the second peak in the region of the 11-kb ELF could not have been detected in the earlier ELF hybridization study (Burhans et al. 1986), since the target clones in that study did not encompass most of this fragment. This omission ultimately contributed to the emerging powerful notion that R1-F' contained the major initiation site in the DHFR locus. As we will see, we also misinterpreted our own data by assuming that the pyramidal shape of the peaks detected in the in-gel studies resulted from fixed start sites that fired at slightly different times in different peaks represent a PCR-based small nascent strand abundance assay utilizing primer pairs distributed out the $12-\mathrm{kb}$ region shown in the figure. b A panel showing the results of neutral/ neutral 2-D gel analysis of this region using two different enzymes (EcoRI and $X b a \mathrm{I})$ to prepare the replication intermediates. The brackets indicate those fragments that reside within the intergenic region itself, while the flanking fragments were derived from the genes

cells in the population owing to imperfect synchrony (as illustrated in Fig. 1). This misconception arose directly from the similar patterns of labeling between our data and that obtained in the comparable experiment on E. coli, whose origin is fixed (Marsh and Worcel 1977). In addition, because the fragments between and flanking the 6- and 11-kb EcoRI fragments were all small, thus rendering their signals relatively weak, there was no reason to believe that these fragments contained initiation sites.

The presence of two origins in the spacer (ori- $\beta$ and ori- $\gamma$ ) was further suggested by an independent study in which CHOC400 cells were treated at the $\mathrm{G}_{1} / \mathrm{S}$ border with psoralen to cross-link the double strands together every $10 \mathrm{~kb}$ or so, followed by release into BrdU or ${ }^{3} \mathrm{H}$-thymidine for a brief interval to label just the DNA close to origins (Anachkova and Hamlin 1989). The 6- and 11-kb ELFs were again shown to be the most highly labeled as cells entered $\mathrm{S}$ phase. 
Interestingly, the $6-\mathrm{kb}$ ori- $\beta$-containing fragment was subsequently shown to contain a highly repetitive AluI element (Leu et al. 1990).

Thus, it was beginning to look like origins in mammalian cells might correspond to specific sites (and potentially to replicators). The presence of a repetitive element in the ori- $\beta$ locus even suggested that at least some origins might share important sequences, although no AluI elements were present in the equally active ori- $\gamma$ locus. The finding of an AluI element in R1-F' presumably did not affect the in vivo labeling patterns of fragments separated by their unique sizes in gels (Heintz and Hamlin 1982; Leu and Hamlin 1989). However, the presence of the repeated element in or near ori- $\beta$ obviously clouded studies in which early-labeled DNA was used as a hybridization probe on cloned sequences from the region (Burhans et al. 1986; Anachkova and Hamlin 1989), since the labeled AluI elements could have come from early-firing origins elsewhere in the genome. It would clearly be difficult to correct hybridization intensities for AluI elements, since using high $C_{0}$ t DNA to block them from the probe totally eliminated hybridization to R1-F', probably by forming networks with adjacent unique sequences in the region (Anachkova and Hamlin 1989). Thus, it is likely that the presence of an AluI element in R1-F' was partially responsible for this fragment appearing to be the most active in the region.

For reasons that are difficult to fully understand even now, from this time onward, it was assumed by almost all but ourselves that ori- $\beta$ was the most active site in the DHFR locus and therefore probably corresponded to a replicator. Ori- $\gamma$ was essentially ignored for years, even though we now thought of it as the second origin in the region. As we will see, even this was a misinterpretation and oversimplification of our own data.

Identifying origins by localizing the positions at which leading and lagging strands switch templates Meanwhile, others were devising their own in vivo labeling schemes to follow replication forks (and potentially identify initiation sites) in mammalian genomes. Two potentially powerful approaches appeared in 1989 and 1990 , both of which were initially tested on the Chinese hamster DHFR locus. These methods rely on the fact that leading and lagging strands switch templates at initiation sites (Fig. 1). The first technique (Roufa and Marchionni 1982) depended on an older suggestion that nucleosomes are distributed only to the leading strand at the replication fork (Seidman et al. 1979). Hence, partial inhibition of protein (and thereby histone) synthesis with emetine in the presence of BrdU should allow nucleosome-free DNA to accumulate on the slowly elongating, BrdUlabeled retrograde arm of each fork. This should subsequently be degraded preferentially with micrococcal nuclease, leaving the nucleosome-protected $145 \mathrm{bp}$ of DNA on the leading strand largely intact. Isolation of heavy single-stranded DNA and hybridization to the plus and minus strands of M13 clones encompassing a region of interest should then indicate where the template switches and therefore the position of the origin (Fig. 1).

In fact, in the first application to a mammalian cell line (Handeli et al. 1989), the DHFR origin was used as the positive control, with the expectation that the switch would occur at ori- $\beta$. Instead, two switches were observed - one at ori- $\beta$ and one encompassing ori- $\gamma$. Since our lab was in the act of publishing the high-resolution in-gel renaturation experiments identifying these two preferred early-labeled regions, this study constituted a critical independent confirmation of the existence of these two regions as likely to contain origins of replication. The theoretical power of this technique is that it should allow an initiation site to be mapped within a few nucleosomes of the start site if it is fixed and efficient. In fact, the primary data painted a much less clear picture: the degree of bias varied substantially across the $\sim 35-\mathrm{kb}$ core region of the DHFR intergenic region, but nowhere was it as great as in the DHFR gene itself. It turns out that the variable and underwhelming biases were probably a mixture of reality (see below) and the inherent lack of precision of the method itself, neither of which could have been appreciated by the authors or by us at the time.

The second fork direction method was based on the original experiments that were used to demonstrate the presence of RNA primers on the $5^{\prime}$ ends of leading and lagging nascent strands, and subsequently to map the sites of initiation around E. coli oriC and SV40 ori, respectively (Okazaki et al. 1975; Kurosawa et al. 1975; Hay and DePamphilis 1982). In this method, the 5 ' ends of RNA-primed leading and lagging strands are selectively labeled with ${ }^{32} \mathrm{P}$ after exposure of the $5^{\prime}$ $\mathrm{OH}$ at the RNA-DNA primer junctions by base 
treatment. The labeled DNA is then utilized to probe the separated strands of the region of interest to localize the template switch and, by inference, the approximate start site. When a 4-kb region encompassing ori- $\beta$ in the Chinese hamster DHFR locus was analyzed by this lagging strand assay, quantitative analysis suggested that more than $80 \%$ of the Okazaki fragments switched templates within this region (Burhans et al. 1990). The same result was observed whether the Okazaki fragments were isolated in early $\mathrm{S}$ phase when the origin is firing or from unsynchronized cell populations. It was concluded that ori- $\beta$ represented the major initiation site in the intergenic spacer, even though the rest of the intergenic spacer was not sampled.

Thus, it appeared that this method could give a very high-resolution picture of replication start sites in defined regions of complex genomes and that mammalian origins might be just as efficient as, say, oriC. This would require, however, that ori- $\gamma$ not be active and, if it were, something would have to prevent forks from entering ori- $\beta$ in early $S$ phase (e.g., a replication fork block). The origin also would have to be almost $100 \%$ efficient to explain why there was such a large bias in template usage at ori- $\beta$ in logphase cells. However, we already had very good evidence that initiation occurs in this locus probably in fewer than $30 \%$ of cell cycles, so that passive replication was occurring in the other $70 \%$. In addition, we could not repeat these results in our own laboratory in a later study - even in early S-phase cells (Wang et al. 1998). At the present time, we still cannot fully reconcile these two studies with each other or with later studies described below.

There was another critical outcome of the latter two studies. The laboratories that initiated this pair of "lagging" strand assays discovered that they were actually observing preferential hybridization of their preparations to the opposite strands in the DHFR locus. It was later shown in a careful analysis that emetine actually allows preferential incorporation of BrdU into the leading strand because it inhibits Okazaki strand synthesis (Burhans et al. 1991). Thus, overnight, this "lagging strand" assay became a "leading strand" assay. Ultimately, results of the two methods were shown to be somewhat concordant with each other, although the biases observed in the leading strand assay (Handeli et al. 1989) never approached those suggested by its complement (Burhans et al. 1990).
Localizing origins by identifying the positions of small nascent strands along the template Concurrent with this large set of somewhat different labeling studies was the development of an approach that could potentially allow the isolation of a comprehensive set of origin-centered DNA with relatively high resolution and, importantly, from diploid loci. The diagram in Fig. 1 points out that nascent strands are approximately centered over the replication initiation site. Were the smallest origin-centered fragments to be released and purified away from the template, their approximate copy numbers at different positions in a region could be quantified using polymerase chain reaction (PCR). Two approaches have been used to release nascent strands: (1) branch migration to yield double-stranded intermediates (Kaufmann et al. 1985) and (2) heating well above the melting temperature to release BrdU-labeled single-stranded nascent strands from the template (Vassilev and Johnson 1989; Vassilev et al. 1990).

We will focus on the second method since the Chinese hamster DHFR locus was among the first mammalian origins to be analyzed by this approach (Vassilev et al. 1990). Log-phase cells were pulselabeled with BrdU; nascent strands were separated from the template by alkaline denaturation and were size-fractionated on alkaline sucrose gradients. AntiBrdU was utilized to isolate the nascent strands, and selected regions of the $\sim 4-\mathrm{kb}$ region encompassing ori- $\beta$ were amplified by PCR using appropriate primers. The products were then quantified by utilizing ${ }^{32} \mathrm{P}$-labeled cognate oligonucleotides to probe dot blots of the PCR products. The resulting data showed a clear enrichment of sequences encompassing the ori- $\beta$ region as identified in previous studies (Burhans et al. 1986; Anachkova and Hamlin 1989; Leu and Hamlin 1989; Burhans et al. 1990; Leu et al. 1990). Thus, the argument that ori- $\beta$ was the major start site in the region was once again bolstered, even though the region encompassing ori- $\gamma$ and the rest of the spacer was not examined.

Two-dimensional gel analysis suggests a noncanonical mode of initiation in the DHFR and other origins of replication While the nascent strand assay was being improved in other labs, two powerful twodimensional (2-D) gel replicon mapping techniques came on the scene in 1987, the application of which completely changed our understanding of the DHFR 
origin and seemed to align almost all of the data from our own and other labs into one unified picture. These two methods provide a very comprehensive view of replication fork movement that simply cannot be obtained by any of the methods discussed previously. In our view, these two methods represent the gold standards for replicon mapping-primarily because they are by definition more than one dimensional.

The first method depends on the different hydrodynamic properties of restriction fragments in an electric field depending on whether they are linear or contain internal bubbles (start sites), single forks, or X-shaped termination structures (Brewer and Fangman 1987). The method was developed to determine whether ARS elements from $S$. cerevisiae behave as origins in the chromosome, but we were able to adapt it to the DHFR locus in CHOC400 cells owing to its high copy number (Vaughn et al. 1990a). The challenge was to retain fragile replication intermediates intact, as the very long mammalian chromosomal DNA fibers are inordinately subject to shear. In our initial studies, DNA from early $\mathrm{S}$ phase or log cultures was crosslinked in vivo with psoralen, purified by standard extraction methods, and digested with a restriction enzyme. Alternatively, we took advantage of the observation that DNA remains supercoiled and attached to an insoluble proteinaceous matrix after histones and other nonhistone chromosomal proteins are extracted from nuclei with isotonic LIS (Mirkovitch et al. 1984). These DNA/halo structures then were digested to completion with a restriction enzyme and the replication intermediates enriched by adsorption to benzoylated naphthoylated diethylaminoethyl (BND) cellulose (Vaughn et al. 1990a). The resulting digests were separated by neutral/neutral 2-D gel electrophoresis (Brewer and Fangman 1987) and transferred to membranes.

Surprisingly, hybridization with probes from the intergenic spacer detected faint bubble arcs not only in the fragments containing ori- $\beta$ and ori- $\gamma$ but in several other fragments within the spacer, regardless of the method utilized to purify the DNA (Vaughn et al. 1990a; Fig. 2b). In addition, however, the bubble arcs were accompanied by much stronger single fork arcs, indicating that they were often replicated passively. Since it was shown that forks from upstream or downstream origins had not yet entered the locus at this early time in S phase, we reasoned that the single forks must have arisen from neighbor- ing fragments within the intergenic spacer itself. Importantly, no bubbles were observed in the DHFR gene, regardless of the position in $\mathrm{S}$ phase and consistent with all of our other studies. Since we also detected faint bubble arcs in fragments isolated from log-phase cultures, it was unlikely that the synchronization protocol itself generated this unusual initiation pattern (Vaughn et al. 1990a; Dijkwel et al. 1994).

In the same study, we adapted a second powerful neutral/alkaline 2-D gel technique that was also developed to study yeast origins in chromosomes (Nawotka and Huberman 1988). The method essentially measures fork direction in any given fragment for which suitable probes can be developed. The first dimension gel again separates replication intermediates by size; however, the lane is then excised, soaked in alkali, turned through $90^{\circ}$, and nascent strands released from their templates by electrophoresis in alkali. After transfer to a membrane, hybridization with small probes reveals the size and origin of the small nascent strands. If a probe centered in a fragment detects nascent strands of all sizes, there must have been initiations at the position of the probe. If an end probe detects a complete nascent strand arc, then single forks must be entering that fragment from outside. If probes from each end detect complete nascent arcs, then the fragment is being replicated passively from both directions.

These three outcomes are exactly what we observed in several fragments from the intergenic region, which indicated that not only were initiations occurring in the middle of many fragments but that the same fragments were also replicated passively in many of the cells by forks entering from either side. Again, all this was happening early in $\mathrm{S}$ phase before forks could be entering the region from distant origins.

There were three general critical reactions to this study both from our own and other laboratories: (1) the matrix-enrichment scheme used to purify intermediates for analysis on 2-D gels could possibly influence the results; (2) bubble- and single-forkcontaining fragments might migrate differently than their bona fide counterparts detected in ARS elements in yeast; and (3) amplification itself somehow might have deranged the normal initiation reaction in the DHFR locus. We had essentially ruled out the first proposition by demonstrating that there is no bias for or against any particular type of replication intermediate in the matrix-enrichment scheme (Vaughn et al. 
1990a, b; Dijkwel et al. 1991). To address the second possibility, yeast and $\mathrm{CHO}$ restriction digests were mixed and run together in the same neutral/neutral 2-D gel (Brun et al. 1995). Probes were selected for initiating fragments of the identical size in the two digests and were labeled with different-colored fluors. When the signals for each of the bubble-containing fragments on the blots were merged, they were clearly identical in shape. Likewise, the single-fork arc in the CHO DNA was coincident with that of a nonorigin fragment from yeast.

To address the third possibility (derangements resulting from amplification), it was clear that we needed to perform 2-D gel analysis on the diploid DHFR locus in $\mathrm{CHO}$ cells, which required at least a $\sim 300$-fold increase in sensitivity and a similar increase in the purity of the replication intermediates. We were able to take advantage of the observation that replication forks selectively and quantitatively partition with the $8-10 \%$ of the DNA that remains attached to the nuclear matrix after digestion of matrix/DNA halo structures with a six-mer restriction enzyme (Vaughn et al. 1990b). Subsequent chromatography over BND cellulose provided an additional 10-15-fold enrichment, resulting in sufficiently pure preparations to allow analysis on 2-D gels (Dijkwel et al. 1991).

When the single-copy DHFR locus in early S-phase $\mathrm{CHO}$ cells was analyzed on neutral/neutral 2-D gels (Dijkwel and Hamlin 1995), the result was virtually identical to that obtained with $\mathrm{CHOC} 400$ cells: every restriction fragment within the intergenic spacer demonstrated a complete bubble arc along with a more prominent single-fork arc - a characteristic we have come to recognize as the signature of fragments residing in initiation zones in the early $\mathrm{S}$ phase. This same composite pattern also was observed in the ori- $\beta$ containing fragment in log-phase cells. Furthermore, neutral/alkaline 2-D gel analysis showed that forks move in both directions in the intergenic region but only outward through the DHFR gene. Thus, we could conclude that the delocalized initiation mode observed in CHOC400 cells was not the consequence of amplification per se.

Importantly, both this study and earlier ones on CHOC400 cells showed that initiation occurred in only a fraction of cell cycles, since single-fork arcs indicative of passive replication persisted in the intergenic region hours after initiation in the locus ceased (Vaughn et al. 1990b; Dijkwel and Hamlin 1992, 1995). Thus, it appears that this origin is very inefficient overall, probably firing in fewer than 30\% of cell cycles, based on the fact that single forks persist in the locus for $6 \mathrm{~h}$ even though initiation ceases after about $2 \mathrm{~h}$. Studies summarized below suggest that this may be true for most mammalian origins. It was later shown that this same dispersive initiation pattern characterizes the rhodopsin origin in CHO cells (Dijkwel et al. 2000), and 2-D gel approaches demonstrated the same characteristics for the rDNA origin residing in the nontranscribed spacer of human cells (Little et al. 1993). Thus, the term "initiation zone" haltingly became a part of the replication lexicon.

Cell synchronizing regimens become an issue I learned several years ago that if one released $\mathrm{CHO}$ cells from a $\mathrm{G}_{0}$ block into hydroxyurea (HU), an inhibitor of ribonucleotide reductase, for times longer than about $10 \mathrm{~h}$, the cells slowly leaked into the $\mathrm{S}$ period (Hamlin and Pardee 1976; J.L. Hamlin, unpublished observations). This made sense because $\mathrm{HU}$ is not expected to prevent origins from firing but only to slow replication forks as they moved away from their start sites. Several years later, HU was generally replaced in mammalian cell synchronization protocols with aphidicolin, which is a deoxycytidine analog that competitively inhibits several DNA polymerases (see Huberman 1981 for an early review). Although aphidicolin gives a reasonably tight block as cells enter $\mathrm{S}$ phase, it is also somewhat leaky: relatively insensitive fluorescence-activated cell sorter analysis suggests that cells are still lined up at the $G_{1} / S$ boundary when collected with aphidicolin, but the intense scrutiny of neutral/neutral 2-D gel analysis on the DHFR origin showed that replication forks had actually traveled considerable distances even after only $12 \mathrm{~h}$ in this drug (Vaughn et al. 1990a; Mosca et al. 1992).

About this time, the plant amino acid, mimosine, was discovered to have effects on the mammalian cell cycle (Lalande 1990), and we showed with 2-D gels that it essentially prevents replication fork formation at origins (Dijkwel and Hamlin 1992; Mosca et al. 1992). Although there is still uncertainty as to how this inhibitor actually works (Mosca et al. 1992; Gilbert et al. 1995), the fact that it synchronizes an advancing $G_{1}$ population prior to chain elongation 
was instrumental in our being able to detect bubble arcs in single-copy loci.

These observations raise the question of whether sequences that are radiolabeled as cells enter $\mathrm{S}$ phase after a lengthy aphidicolin or HU block are really representative of the earliest-replicating sequences in undisturbed cultures (Heintz and Hamlin 1982; Tribioli et al. 1987). Indeed, a prodigious amount of new information suggests that cells activate checkpoints when established forks are slowed (reviewed in Harper and Elledge 2007), and a single-molecule fiber fluorescent in situ hybridization analysis showed clearly that inchoate origins can be activated (or the timing changed) when nucleotide pools are lowered in S-phase cells (Anglana et al. 2003). These phenomena could figure importantly in double block synchronizing protocols required for cell types that cannot be arrested in $G_{0}$ by nutritional or serum starvation because the first step is to add $\mathrm{HU}$ or aphidicolin directly to asynchronous cells, many of which are in S phase.

Results from nascent strand abundance and 2-D gel assays begin to converge - but not meet During the next few years, the small nascent strand abundance assay was improved to correct for differences in PCR amplification efficiencies among different sequences (Pelizon et al. 1996): the PCR reactions were spiked with known amounts of cloned sequences corresponding to each region being queried, but to which an additional 20 bp of unrelated sequence was added in order to compare nascent strand concentrations to that of these standards. In a reanalysis of the DHFR origin from log-phase $\mathrm{CHO}$ cells (again focusing only on the ori- $\beta$ region), the results using this improvement were essentially in agreement with the earlier published work (Vassilev et al. 1990).

About the same time, an extremely interesting system was developed in which nuclei purified from CHOC400 cells in late- $\mathrm{G}_{1}$ (but prior to S-phase entry) were shown to initiate replication (apparently faithfully) when introduced into an in vitro replication cocktail prepared with Xenopus laevis egg extracts (Gilbert et al. 1995). This hybrid system allowed early-replicating regions of the genome to be labeled to very high specific activity with ${ }^{32} \mathrm{P}$-labeled dNTPs. When this labeled material was utilized to probe an extensive series of single-copy cloned fragments from the DHFR intergenic region, the results again indicated that the ori- $\beta$ region was the most intensely labeled. However, this series of probes again excluded the entire 30-kb region encompassing the ori- $\gamma$ locus, bolstering the false assumption that ori- $\beta$ contained the major start site in the region.

A few years later, it was realized by many that, regardless of the precision of the measurements, BrdU labeling created an AT-rich bias in the nascent DNA that was being analyzed. Without it, however, there would be nothing to distinguish nascent DNA from small broken template DNA of the same size, which creates the major chemical mass in the sucrose gradient fractions. The alkaline conditions used to melt and subsequently separate the DNA was obviously also contributing to breakage. In a real tour-de-force, a method was developed in which $\lambda$-exonuclease was used to digest away small DNA resulting from shear, while leaving the RNA-primed nascent strands intact (Bielinsky and Gerbi 1998). The method was perfected on ARS1 from $S$. cerevisiae and yielded such a clean product in their hands that it was even possible to map the positions of the RNA-DNA transitions at start sites to the base pair, as had been accomplished previously for SV40 (Hay and DePamphilis 1982). In a recent application to a mammalian origin, the RNA-DNA transitions at start sites were also mapped to the base pair in the human lamin B2 origin (Abdurashidova et al. 2000). This origin was discovered in an earlylabeling strategy (Tribioli et al. 1987) and subsequently fine-mapped by an earlier version of the nascent strand abundance assay (Giacca et al. 1994). This is one of the few examples of a mammalian origin that appears to behave like the replicators of simple genomes. Interestingly, lamin B2 resides in a very narrow intergenic region; therefore, it may be able to accommodate only one of the prereplication complexes required to effect initiation. In fact, certain mutated versions of a short sequence encompassing this locus do initiate less efficiently when tested at ectopic positions, which supports the replicator concept for this locus (Paixao et al. 2004).

Inspired by this apparent improvement, a more extensive analysis was repeated on the $12-\mathrm{kb}$ region encompassing both of the 6-kb EcoRI ELFs that were originally identified in the DHFR locus (Burhans et al. 1986; Leu and Hamlin 1989) but once again excluding the region to the right encompassing ori- $\gamma$. A much larger number of closely spaced primer pairs were utilized in competitive PCR assays on nascent early S-phase DNA prepared by BrdU labeling and immunoprecipitation or without BrdU but including 
the $\lambda$-exonuclease treatment (Kobayashi et al. 1998). In fact, in this report, there was precious little difference in the apparent distribution of nascent strands obtained by the two methods. The important finding, however, was that focusing on this extended region now illuminated two peaks - one corresponding to ori- $\beta$ and one to its immediate right, which was termed ori- $\beta^{\prime}$. As it turns out, each peak resides in one of the two 6-kb EcoR1 ELFs.

In hindsight, the focus on this $12-\mathrm{kb}$ region as opposed to the entire 55-kb spacer is understandable, given the emotional bias toward the 6-kb ELFs, as well as the huge number of competitor clones and primer sets that would have been required to scan the whole locus. The latter problem has been partially alleviated with the advent of real-time PCR, which is now used in place of the competitive PCR reaction (e.g., Wang et al. 2004).

We realized that had the whole intergenic region been analyzed with such precision other initiation sites might be detected (ori- $\gamma$ being one of them). Since elaborating all the necessary primer pairs would have been a formidable task, we labeled nascent strands in vitro with ${ }^{32} \mathrm{P}$-dCTP after releasing CHOC 400 cells from a $\mathrm{G}_{1} / \mathrm{S}$ mimosine block, isolated the 300-1,000-nt labeled nascent strands on gels, and hybridized them to dot blots of 22 small single-copy sequences spread across the intergenic region and separated from one another by more than $1,500 \mathrm{bp}$.

The pattern we saw was striking (Fig. 2, solid curve; Dijkwel et al. 2002). The ori- $\beta$ and ori- $\gamma$ regions were clearly the most highly labeled, but a shoulder appeared on the right side of the ori- $\beta$ peak, which coincides with the ori- $\beta^{\prime}$ peak detected in the independent study (Kobayashi et al. 1998). The central region of the spacer appeared to be devoid of nascent strands, in agreement with the pattern suggested by the earlier in-gel renaturation ELF studies (Leu and Hamlin 1989). Importantly, this experiment showed that under these circumstances, initiation must be occurring at least at each of the 22 positions represented by the dot-blotted fragments, since the distances between these fragments are greater than the size of the nascent strand probe itself (300-1,000 nt). In our minds, these data constitute one of the most compelling arguments that the DHFR origin corresponds to an initiation zone. Using a very similar strategy but with a large number of probes, the same conclusion was arrived at in a different laboratory (Sasaki et al. 2006).
Some aspects of the small nascent strand abundance assay are worth considering, particularly their numbers in a log-phase culture at any instant and the difficulty of purifying them away from template. If the average fork rate is $\sim 2 \mathrm{~kb}$ a minute, then any region encompassing an initiation site will contain nascent strands $2 \mathrm{knt}$ in length for only $\sim 0.5 \mathrm{~min}$. If the cell cycle time is $20 \mathrm{~h}$ $(1,200 \mathrm{~min})$, then only $1 / 2,400$ of the DNA corresponding to this $2-\mathrm{kb}$ region will represent nascent strands, with the vast majority corresponding to nonreplicating template with exactly the same chemical properties. Typically, one starts with $10^{8}$ cells, which contain $2 \times 10^{8}$ copies of the locus in question, of which $8 \times 10^{4}(1 / 2400$ th $)$ will be nascent. If there are $\sim 5 \times 10^{4}$ origins in the cell, then a saturating preparation of nascent strands for all sites would correspond to $4 \times 10^{9} 2 \mathrm{knt}$ nascent strands. However, our current whole-genome studies indicate that at least half of the origins are zones (Mesner et al. submitted). Thus, assuming that the average zone might have at least three independent start sites, the total number of nascent strands would be $2 \times 10^{9}+\left(2 \times 10^{9}\right)(3)$, which equals about $8 \times 10^{9}$ nascent strands total. With an expected efficiency of $\sim 50 \%$, this would amount to 5-10 ng of purified nascent DNA starting with $600 \mu \mathrm{g}$ from $10^{8}$ cells - a formidable purification obstacle.

In early incarnations, "nascent strands" were obtained after a BrdU pulse, followed only by heating or treatment with alkali and a sizing step on sucrose gradients. Eliminating the BrdU pulse and introducing $\lambda$-exonuclease in some laboratories can apparently provide a cleaner preparation, although this enzyme greatly prefers double-stranded templates for full activity. Even in the most recent studies, the variation in yields among samples prepared in the same lab from the same cells can be as much as sixfold (Cadoret et al. 2008). Thus, the degrees of purity can be quite variable. Rarely is there an attempt to analyze the exact composition of the material that is considered to be "nascent" except by searching for the presence of sites that were identified in material purified by the very same method (e.g., lamin B2 and c-myc).

Trying to reconcile data from different views of the DHFR origin Needless to say, for those not working directly on the DHFR locus, it was extremely difficult to sort out the conflicting pictures being painted by the various laboratories working on this locus. The early 
in-gel renaturation studies (Leu and Hamlin 1989), the in vitro ELF data (Dijkwel et al. 2002), and the 2-D gel analyses (Vaughn et al. 1990a; Dijkwel and Hamlin 1992) all indicated that there were at least two preferred initiation regions (ori- $\beta$ and ori- $\gamma$ ) within the intergenic spacer, not just one at ori- $\beta$. Rather than corresponding to fixed sites, these regions appeared to be just somewhat preferred over many other sites scattered throughout the spacer, with a relative dead zone approximately in its center (Leu and Hamlin 1989; Dijkwel et al. 2002). Only in the most recent nascent strand abundance approach from another laboratory was it suggested that there was more than one preferred start site (ori- $\beta$ and ori- $\beta^{\prime}$ at least; Kobayashi et al. 1998), and the title of this paper now used the moniker initiation zone to describe the DHFR origin.

Even these data were not entirely in agreement with $2-\mathrm{D}$ gel analyses. The region between ori- $\beta$ and ori- $\beta^{\prime}$ appeared to be devoid of small nascent strands in the most extensive small nascent strand analysis (Kobayashi et al. 1998), again reinforcing the concept that the two corresponded to fixed sites and therefore probably replicators. However, we were able to demonstrate that a small fragment straddling this presumed negative region actually displays a bubble arc on 2-D gels (Dijkwel et al. 2002). If bubblecontaining fragments give rise to small nascent strands, as most of us assume, this result suggests that perhaps the small nascent strand preparations are not saturating. If that were the case, then it would not be surprising to find them populated only with the most efficient initiation sites. Importantly, no amount of PCR amplification could detect the less efficient start sites if they are not present in the preparation, although, in theory, they could constitute the majority of start sites in the genome.

A few other points are worth making here. Since none of the nascent strand preparations that we and others have utilized to localize start sites are very pure, one normally utilizes total genomic DNA isolated from log-phase cells as a normalization standard. Since early-replicating loci are overrepresented in this kind of sample, all sequences in this standard are not at equal copy number (although the variance is not huge). Another extremely important observation was made recently: there is an apparent futile replication cycle of double-stranded DNA sequences, which results in amplification of the template as much as 40-50-fold (Gomez and Antequera 2008). This material is 200 bp long, is RNA-primed, and is highly enriched in $\mathrm{CpG}$ islands, but there is no solid evidence that any of this material ever matures into finished replicons. Because this very abundant material sediments dangerously close to the fractions that are selected as "small nascent strands" in sucrose gradients, the possibility arises that a major contaminant of some nascent strand preparations may not be legitimate.

Thus, what we all call nascent strands could be significantly contaminated with broken, nonnascent DNA, could fail to be saturating, and could even include CpG-island-enriched DNA that really has nothing to do with true origins.

\section{Genetic analyses identify required cis-elements}

The ability to perform 2-D gel analysis on diploid loci in mammalian cells marked an important shift in emphasis in our laboratory, as we no longer had to rely on the amplified cell line to analyze this complex origin. This opened the way for genetic studies on the single-copy locus that ultimately allowed a search for any genetic elements that are required to effect initiation in the spacer. Owing to the availability of CHO variants that had only a single DHFR locus, as well as several $d h f r$-deficient derivatives that were missing parts of the gene, we were able to develop a strategy for restoring the gene to wild type while introducing small deletions into the downstream origin (Kalejta et al. 1998).

We first addressed the possibility that, although initiation occurs at an array of sites in the spacer in different cells in the population, ori- $\beta$, ori- $\beta^{\prime}$, or ori- $\gamma$ might actually correspond to true replicators. One would only have to assume that, after melting the helix at these sites, a helicase migrates back and forth in a random walk before the RNA primer is loaded (i.e., initiation and chain elongation are uncoupled in time). To address this possibility, we first deleted ori- $\beta$, then a combination of ori- $\beta$ and ori- $\beta^{\prime}$, and finally the entire $45 \mathrm{~kb}$ that encompasses $>90 \%$ of the start sites in the 55-kb intergenic spacer (Kalejta et al. 1998; Mesner et al. 2003). The results of this analysis were striking: there was no discernible effect of deleting ori- $\beta$ or ori- $\beta$ and ori- $\beta^{\prime}$, on initiation in the 
rest of the spacer, as judged by 2-D gel analysis or by a replication timing assay. Surprisingly, even when the central $45 \mathrm{~kb}$ was deleted, initiation in the truncated $10-\mathrm{kb}$ spacer actually increased in efficiency, with the consequence that the locus still initiated and replicated in early S phase (Mesner et al. 2003). These experiments showed clearly that there are no critical nonredundant elements in the DHFR origin itself that are required to effect initiation.

The question then arose whether any cis-regulatory elements are necessary for maximum origin activity. It turns out that sequences in the promoter of the DHFR gene that are required for transcription are also required to enhance the downstream origin since, in their absence, the overall efficiency of the origin decreases (Saha et al. 2004). Amazingly, however, the promoter deletion allowed the initiation zone to spread into the body of the now-inactive gene. This important observation showed clearly that even the bodies of genes contain inchoate initiation sites that are silenced by read-through transcription. This view was reinforced by the observation that deletion of the 3' termination signals of the DHFR gene, which allowed transcription of all but $8 \mathrm{~kb}$ of the intergenic spacer, completely prevented this region from initiating replication (Mesner and Hamlin 2005). In the remaining 8-kb intergenic region near the end of the 2BE2121 gene, the efficiency of initiation was again greatly increased over that of the same sequences in the wildtype arrangement, presumably because some limiting factors required for initiation are now distributed over a much smaller number of potential initiation sites. Finally, we recently demonstrated that fragments containing either ori- $\beta$, ori- $\beta^{\prime}$, or a fragment from the body of the DHFR gene all initiate with approximately the same efficiency when inserted at ectopic anonymous positions, in the CHO genome (Lin et al. 2005). This is in spite of the fact that the gene fragment never initiates at its native locus.

Even these relatively straightforward results have not deterred other laboratories from attempting to determine the sequence elements in ori- $\beta$ that render it an efficient site relative to other sites in the spacer (although we have calculated that the $4-\mathrm{kb}$ region encompassing it fires in fewer than $5 \%$ of cell cycles in a $\log$ population; J.L. Hamlin, unpublished). The approach has been to introduce small deletions into a cloned fragment encompassing ori- $\beta$ to insert it either at random anonymous or specific ectopic positions in a human cell line and then to use the small nascent strand abundance assay to measure activities relative to some local marker adjudged to be initiation negative (Altman and Fanning 2001, 2004; Gray et al. 2007). There are, indeed, small sequences that can be deleted from ori- $\beta$ that lower its efficiency, suggesting that they may help to attract the initiation machinery to this site in vivo. Given that none of the sites in the spacer are essential (including ori- $\beta$ ), we suggest that the old idea of replicators may not pertain to sites within initiation zones. As mentioned earlier, the lamin B2 origin appears to require certain sequences for full activity (Paixao et al. 2004), as do the $c$-myc and $\beta$-globin initiation zones (Liu et al. 2003; Wang et al. 2004).

\section{Testing this general model at the genome-wide level}

All of these studies on the DHFR locus have led us to a model in which the entire mammalian genome is peppered with a hierarchy of degenerate initiation sites, the use of which is governed by local transcription both positively and negatively. We have used the analogy to DNAse-hypersensitive sites in naked DNA, some of which are clearly preferred over other sites, but we do not consider DNAseI or micrococcal nuclease to be sitespecific endonucleases (Hamlin et al. 2008). Of course, this model arose largely from our studies on the DHFR locus and departs considerably from the expectation that regulation of replication in mammals generally would obey the same rules that apply to lower organisms. We therefore wanted to devise a method for isolating and mapping all of the active initiation sites in the genome in order to test our general model.

We devised a strategy for purifying restriction fragments that contained active initiation sites in vivo (Mesner et al. 2006) and have made recombinant libraries from a cancerous human cell variant (HeLa) as well as from the near-normal lymphoblastoid GM06990 cell line. The strategy involves the preferential entrapment of bubble-containing restriction fragments in gelling agarose. After purification and cloning of the entrapped fragments, the libraries were hybridized to microarrays from $1 \%$ of the human genome under study by the ENCODE consortium (Mesner et al., submitted). These studies show that half of the fragments in these libraries map at isolated 
positions in the genome and thus could contain single sites or small zones, while the other half cluster together in groups of two to 18 fragments and probably represent initiation zones (the average is $\sim 18 \mathrm{~kb}$ in length, with a range of 2 to $180 \mathrm{~kb}$ ). Interestingly, the signal strengths of isolated fragments that could contain relatively fixed sites are well below the signals of the average fragment in a zone, suggesting that isolated sites are not generally more active than sites within zones. Origin distributions show clearly that intergenic sequences are not preferred over genic ones. This finding is consistent with studies on the DHFR promoter deletion showing that the gene itself is a perfectly good substrate for initiation when it is not transcribed (Saha et al. 2004) or when not transcribed at an ectopic position (Lin et al. 2005). All these findings therefore suggest to us that there is unlikely to be a strong selection for "replicators" in mammalian genomes. However, there is a significant association between bubble-containing fragments and neighboring active genes (Mesner et al., submitted), supporting the long-appreciated relationship between active transcription and early replication.

How do these data compare with origin maps that are being constructed by others using small nascent strands as the starting material? In a recent study that also focused on the ENCODE regions of the genome (Cadoret et al. 2008), five biological replicates of small nascent strands were prepared utilizing $\lambda$-exonuclease to attempt to enrich for RNA-primed nascent strands over small broken template DNA. Careful analysis of the enrichment of the c-myc origin over a nonorigin control showed that individual purities varied more than sixfold among these preparations. When hybridized individually to the microarrays, there was clearly a large amount of background hybridization from irrelevant DNA, but when a stringent cutoff was utilized, there were some very clear positive signals that were common to most of the preparations. In fact, a small number of these positions fell within EcoRI fragments that were recovered in the bubble-trapping protocol (Mesner, et al., submitted).

In general, however, there is very little overlap between the origin map generated with these nascent strand preparations and that generated by bubblecontaining fragments that we have obtained. In part, this could be due to the high cutoffs used in the nascent strand studies to select only the most robust signals, which also renders it likely that the maps presented in this study are far from saturating. Presumably, these signals correspond to only the most active sites in the genome and would select against the identification of initiation zones that encompass many sites with different efficiencies of utilization. The bubble-trapping scheme is also biased toward larger fragments whose bubbles would have longer dwell times and is biased against fragments with very off-centered bubbles. Therefore, our libraries may not be saturating either. While the latter problem could be partially alleviated by utilizing different restriction enzymes to prepare additional libraries, the cost of this approach is currently prohibitive.

In fact, these possibilities may be the major source of discordance between the two approaches: if neither library is saturating, then the degree of overlap will be minimal even if the signals recovered for each type of library might be valid. However, it is probably not the only source of discordance, since in some of the ENCODE regions there appear to be dense concentrations of robust small nascent strand signals that do not coincide with similarly dense trapped bubbles, and in other cases the opposite is true, i.e., bubbles are found where there are very few small nascent strand signals. Overall, our current estimate is that fewer than $15 \%$ of the positive signals from the two preparations overlap (Mesner, et al., submitted). In our view, future studies by our own laboratory and by others should include some carefully crafted analyses of the preparations that are assumed to represent the majority of all start sites in the human genome before any serious take-home messages should be proffered about their overlaps with each other or with genes, $\mathrm{CpG}$ islands, etc. In that way, together, we will all be able to make an important concerted contribution toward understanding the nature of mammalian origins and how they are distributed within the genome.

Acknowledgements We would like to thank all the members of the Hamlin laboratory past and present, who have toiled on this locus throughout the day and gone to sleep at night wondering how to perform the perfectly logical experiment. We also thank the NIH for continued support throughout the years (presently RO1-GM26108 and RO1-HG002937).

\section{References}

Abdurashidova G, Deganuto M, Klima R, Riva S, Biamonti G, Giacca M, Falaschi A (2000) Start sites of bidirectional 
DNA synthesis at the human lamin B2 origin. Science 287 (5460):2023-2026

Altman AL, Fanning E (2001) The Chinese hamster dihydrofolate reductase replication origin beta is active at multiple ectopic chromosomal locations and requires specific DNA sequence elements for activity. Mol Cell Biol 21(4):10981110

Altman AL, Fanning E (2004) Defined sequence modules and an architectural element cooperate to promote initiation at an ectopic mammalian chromosomal replication origin. Mol Cell Biol 24(10):4138-4150

Anachkova B, Hamlin JL (1989) Replication in the amplified dihydrofolate reductase domain in $\mathrm{CHO}$ cells may initiate at two distinct sites. One of which is a repetitive sequence element. Mol Cell Biol 9:532-540

Anglana M, Apiou F, Bensimon A, Debatisse M (2003) Dynamics of DNA replication in mammalian somatic cells: nucleotide pool modulates origin choice and interorigin spacing. Cell 114(3):385-394

Biedler JL, Spengler BA (1976) Metaphase chromosome anomaly: association with drug resistance and cell-specific products. Science 191(4223):185-187

Bielinsky AK, Gerbi SA (1998) Discrete start sites for DNA synthesis in the yeast ARS1 origin. Science 279:95-98

Brewer BJ, Fangman WL (1987) The localization of replication origins on ARS plasmids in S. cerevisiae. Cell 51(3):463471

Brun C, Dijkwel PA, Little RD, Hamlin JL, Schildkraut CL, Huberman JA (1995) Yeast and mammalian replication intermediates migrate similarly in two-dimensional gels. Chromosoma 104(2):92-102

Burhans WC, Selegue JE, Heintz NH (1986) Isolation of the origin of replication associated with the amplified Chinese hamster dihydrofolate reductase domain. Proc Natl Acad Sci U S A 83:7790-7794

Burhans WC, Vassilev LT, Caddle MS, Heintz NH, Depamphilis ML (1990) Identification of an origin of bidirectional DNA replication in mammalian chromosomes. Cell 62(5):955965

Burhans WC, Vassilev LT, Wu J, Sogo JM, Nallaseth FS, Depamphilis ML (1991) Emetine allows identification of origins of mammalian DNA replication by imbalanced DNA synthesis, not through conservative nucleosome segregation. EMBO J 10(13):4351-4360

Cadoret JC, Meisch F, Hassan-Zadeh V, Luyten I, Guillet C, Duret L, Quesneville H, Prioleau MN (2008) Genome-wide studies highlight indirect links between human replication origins and gene regulation. Proc Natl Acad Sci U S A 105 (41):15837-15842

Chan CS, Tye BK (1980) Autonomously replicating sequences in Saccharomyces cerevisiae. Proc Natl Acad Sci U S A 77:6329-6333

Dijkwel PA, Hamlin JL (1992) Initiation of DNA replication in the dihydrofolate reductase locus is confined to the early $\mathrm{S}$ period in $\mathrm{CHO}$ cells synchronized with the plant amino acid mimosine. Mol Cell Biol 12(9):3715-3722

Dijkwel PA, Hamlin JL (1995) The Chinese hamster dihydrofolate reductase origin consists of multiple potential nascent-strand start sites. Mol Cell Biol 15(6):3023-3031

Dijkwel PA, Vaughn JP, Hamlin JL (1991) Mapping of replication initiation sites in mammalian genomes by two-dimensional gel analysis: stabilization and enrichment of replication intermediates by isolation on the nuclear matrix. Mol Cell Biol 11(8):3850-3859

Dijkwel PA, Vaughn JP, Hamlin JL (1994) Replication initiation sites are distributed widely in the amplified CHO dihydrofolate reductase domain. Nucleic Acids Res 22(23):4989-4996

Dijkwel PA, Mesner LD, Levenson VV, D'anna J, Hamlin JL (2000) Dispersive initiation of replication in the Chinese hamster rhodopsin locus. Exp Cell Res 256(1):150-157

Dijkwel PA, Wang S, Hamlin JL (2002) Initiation sites are distributed at frequent intervals in the Chinese hamster dihydrofolate reductase origin of replication but are used with very different efficiencies. Mol Cell Biol 22(9):30533065

Frappier L, Zannis-Hadjopoulos M (1987) Autonomous replication of plasmids bearing monkey DNA origin-enriched sequences. Proc Natl Acad Sci U S A 84:6668-6672

Giacca M, Zentilin L, Norio P, Diviacco S, Dimitrova D, Contreas G, Biamonti G, Perini G, Weighardt F, Riva S (1994) Fine mapping of a replication origin of human DNA. Proc Natl Acad Sci U S A 91(15):7119-7123

Gilbert DM, Neilson A, Miyazawa H, Depamphilis ML, Burhans WC (1995) Mimosine arrests DNA synthesis at replication forks by inhibiting deoxyribonucleotide metabolism. J Biol Chem 270(16):9597-9606

Gomez M, Antequera F (2008) Overreplication of short DNA regions during $\mathrm{S}$ phase in human cells. Genes Dev 22 (3):375-385

Gray SJ, Liu G, Altman AL, Small LE, Fanning E (2007) Discrete functional elements required for initiation activity of the Chinese hamster dihydrofolate reductase origin beta at ectopic chromosomal sites. Exp Cell Res 313(1):109120

Hamlin JL, Pardee AB (1976) S phase synchrony in monolayer CHO cultures. Exp Cell Res 100(2):265-275

Hamlin JL, Mesner LD, Lar O, Torres R, Chodaparambil SV, Wang L (2008) A revisionist replicon model for higher eukaryotic genomes. J Cell Biochem 105(2):321-329

Handeli S, Klar A, Meuth M, Cedar H (1989) Mapping replication units in animal cells. Cell 57(6):909-920

Harper JW, Elledge SJ (2007) The DNA damage response: ten years after. Mol Cell 28(5):739-745

Hay RT, Depamphilis ML (1982) Initiation of SV40 DNA replication in vivo: location and structure of $5^{\prime}$ ends of DNA synthesized in the Ori region. Cell 28:767-779

Heintz NH, Hamlin JL (1982) An amplified chromosomal sequence that includes the gene for dihydrofolate reductase initiates replication within specific restriction fragments. Proc Natl Acad Sci U S A 79(13):4083-4087

Heintz NH, Hamlin JL (1983a) In vivo effects of cytosine arabinoside on deoxyribonucleic acid replication in Chinese hamster ovary cells. 1 Resolution of differential effects on mitochondrial and nuclear deoxyribonucleic acid synthesis. Biochemistry 22(15):3552-3557

Heintz NH, Hamlin JL (1983b) In vivo effects of cytosine arabinoside on deoxyribonucleic acid replication in Chinese hamster ovary cells. 2 Cytosine arabinoside affects the rate of synthesis but not the pattern of labeling of an amplified chromosomal sequence at the onset of the $\mathrm{S}$ period. Biochemistry 22(15):3557-3562 
Heintz NH, Milbrandt JD, Greisen KS, Hamlin JL (1983) Cloning of the initiation region of a mammalian chromosomal replicon. Nature 302(5907):439-441

Heinzel SS, Krysan PJ, Tran CT, Calos MP (1991) Autonomous DNA replication in human cells is affected by the size and the source of the DNA. Mol Cell Biol 11:2263-2272

Herrick J, Bensimon A (2009) Introduction to molecular combing: genomics DNA replication, and cancer. Methods Mol Biol 521:71-101

Holst A, Muller F, Zastrow G, Zentgraf H, Schwender S, Dink1 E, Grummt F (1988) Murine genomic DNA sequences replicating autonomously in mouse L cells. Cell 52:355365

Huberman JA (1981) New views of the biochemistry of eucaryotic DNA replication revealed by aphidicolin, an unusual inhibitor of DNA polymerase alpha. Cell 23 (3):647-648

Huberman JA, Riggs AD (1968) On the mechanism of DNA replication in mammalian chromosomes. J Mol Biol 32 (2):327-341

Jacob F, Brenner S (1963) On the regulation of DNA synthesis in bacteria: the hypothesis of the replicon. C R Hebd Seances Acad Sci 256:298-300

Jin Y, Yie TA, Carothers AM (1995) Non-random deletions at the dihydrofolate reductase locus of Chinese hamster ovary cells induced by alpha-particles simulating radon. Carcinogenesis 16(8):1981-1991

Kalejta RF, Li X, Mesner LD, Dijkwel PA, Lin HB, Hamlin JL (1998) Distal sequences but not Ori-beta/Obr-1, are essential for initiation of DNA replication in the Chinese hamster DHFR origin. Mol Cell 2:797-806

Kaufmann G, Zannis HM, Martin RG (1985) Cloning of nascent monkey DNA synthesized early in the cell cycle. Mol Cell Biol 5:721-727

Kobayashi T, Rein T, Depamphilis ML (1998) Identification of primary initiation sites for DNA replication in the hamster dihydrofolate reductase gene initiation zone. Mol Cell Biol 18:3266-3277

Krysan PJ, Haase SB, Calos MP (1989) Isolation of human sequences that replicate autonomously in human cells. Mol Cell Biol 9(3):1026-1033

Kurosawa Y, Ogawa T, Hirose S, Okazaki T, Okazaki R (1975) Mechanism of DNA chain growth. Xv. RNA-linked nascent DNA pieces in Escherichia coli strains assayed with spleen exonuclease. J Mol Biol 96(4):653-664

Lalande MM (1990) A reversible arrest point in the late G1 phase of the mammalian cell cycle. Exp Cell Res 186:332-339

Leffak M, James CD (1989) Opposite replication polarity of the germ line c-Myc gene in hela cells compared with that of two Burkitt lymphoma cell lines. Mol Cell Biol 9(2):586-593

Leu TH, Hamlin JL (1989) High-resolution mapping of replication fork movement through the amplified dihydrofolate reductase domain in $\mathrm{CHO}$ cells by in-gel renaturation analysis. Mol Cell Biol 9(2):523-531

Leu TH, Anachkova B, Hamlin JL (1990) Repetitive sequence elements in an initiation locus of the amplified dihydrofolate reductase domain in CHO cells. Genomics 7(3):428-433

Lin HB, Dijkwel PA, Hamlin JL (2005) Promiscuous initiation on mammalian chromosomal DNA templates and its possible suppression by transcription. Exp Cell Res 308:53-64
Little RD, Platt TH, Schildkraut CL (1993) Initiation and termination of DNA replication in human RRNA genes. Mol Cell Biol 13(10):6600-6613

Liu G, Malott M, Leffak M (2003) Multiple functional elements comprise a mammalian chromosomal replicator. Mol Cell Biol 23(5):1832-1842

Looney JE, Hamlin JL (1987) Isolation of the amplified dihydrofolate reductase domain from methotrexate-resistant Chinese hamster ovary cells. Mol Cell Biol 7:569-577

Ma C, Leu TH, Hamlin JL (1990) Multiple origins of replication in the dihydrofolate reductase amplicons of a methotrexate-resistant Chinese hamster cell line. Mol Cell Biol 10(4):1338-1346

Marsh RC, Worcel A (1977) A DNA fragment containing the origin of replication of the Escherichia coli chromosome. Proc Natl Acad Sci U S A 74:2720-2724

Mesner LD, Hamlin JL (2005) Specific signals at the 3' end of the DHFR gene define one boundary of the downstream origin of replication. Genes Dev 19(9):1053-1066

Mesner LD, Li X, Dijkwel PA, Hamlin JL (2003) The dihydrofolate reductase origin of replication does not contain any nonredundant genetic elements required for origin activity. Mol Cell Biol 23(3):804-814

Mesner LD, Crawford EL, Hamlin JL (2006) Isolating apparently pure libraries of replication origins from complex genomes. Mol Cell 21(5):719-726

Milbrandt JD, Heintz NH, White WC, Rothman SM, Hamlin JL (1981) Methotrexate-resistant Chinese hamster ovary cells have amplified a 135-kilobase-pair region that includes the dihydrofolate reductase gene. Proc Natl Acad Sci U S A 78(10):6043-6047

Mirkovitch J, Mirault ME, Laemmli UK (1984) Organization of the higher-order chromatin loop: specific DNA attachment sites on nuclear scaffold. Cell 39:223-232

Mosca PJ, Dijkwel PA, Hamlin JL (1992) The plant amino acid mimosine may inhibit initiation at origins of replication in Chinese hamster cells. Mol Cell Biol 12(10):4375-4383 Published erratum appears in Mol Cell Biol 1993, 13:1981

Nawotka KA, Huberman JA (1988) Two-dimensional gel electrophoretic method for mapping DNA replicons. Mol Cell Biol 8(4):1408-1413

Okazaki R, Hirose S, Okazaki T, Ogawa T, Kurosawa Y (1975) Assay of RNA-linked nascent DNA pieces with polynucleotide kinase. Biochem Biophys Res Commun 62 (4):1018-1024

Paixao S, Colaluca IN, Cubells M, Peverali FA, Destro A, Giadrossi S, Giacca M, Falaschi A, Riva S, Biamonti G (2004) Modular structure of the human lamin B2 replicator. Mol Cell Biol 24(7):2958-2967

Pelizon C, Diviacco S, Falaschi A, Giacca M (1996) Highresolution mapping of the origin of DNA replication in the hamster dihydrofolate reductase gene domain by competitive PCR. Mol Cell Biol 16:5358-5364

Prescott DM, Kuempel PL (1972) Bidirectional replication of the chromosome in Escherichia coli. Proc Natl Acad Sci U S A 69(10):2842-2845

Roninson IB (1983) Detection and mapping of homologous repeated and amplified DNA sequences by DNA renaturation in agarose gels. Nucleic Acids Res 11:5413-5431

Roth GE, Blanton HM, Hager LJ, Zakian VA (1983) Isolation and characterization of sequences from mouse chromo- 
somal DNA with ARS function in yeasts. Mol Cell Biol 3 (11):1898-1908

Roufa DJ, Marchionni MA (1982) Nucleosome segregation at a defined mammalian chromosomal site. Proc Natl Acad Sci U S A 79(6):1810-1814

Saha S, Shan Y, Mesner LD, Hamlin JL (2004) The promoter of the Chinese hamster ovary dihydrofolate reductase gene regulates the activity of the local origin and helps define its boundaries. Genes Dev 18(4):397-410

Sasaki T, Ramanathan S, Okuno Y, Kumagai C, Shaikh SS, Gilbert DM (2006) The Chinese hamster dihydrofolate reductase replication origin decision point follows activation of transcription and suppresses initiation of replication within transcription units. Mol Cell Biol 26(3):1051-1062

Schurra C, Bensimon A (2009) Combing genomic DNA for structural and functional studies. Methods Mol Biol 464:71-90

Seidman MM, Levine AJ, Weintraub H (1979) The asymmetric segregation of parental nucleosomes during chromosome replication. Cell 18(2):439-449

Stinchcomb DT, Thomas M, Kelly J, Selker E, Davis RW (1980) Eukaryotic DNA segments capable of autonomous replication in yeast. Proc Natl Acad Sci U S A 77:4559-4563

Tobey RA (1973) Production and characterization of mammalian cells reversibly arrested in G1 by growth in isoleucine-deficient medium. Methods Cell Biol 6:67-112

Tribioli C, Biamonti G, Giacca M, Colonna M, Riva S, Falaschi A (1987) Characterization of human DNA sequences synthesized at the onset of S-phase. Nucleic Acids Res 15(24):10211-10232

Urlaub G, Mitchell PJ, Kas E, Chasin LA, Funanage VL, Myoda TT, Hamlin JL (1986) Effect of gamma rays at the dihydrofolate reductase locus: deletions and inversions. Somat Cell Mol Genet 12(6):555-566

Vassilev LT, Johnson EM (1989) Mapping initiation sites of DNA replication in vivo using polymerase chain reaction amplification of nascent strand segments. Nucleic Acids Res 17:7693-7705

Vassilev LT, Burhans WC, Depamphilis ML (1990) Mapping an origin of DNA replication at a single-copy locus in exponentially proliferating mammalian cells. Mol Cell Biol 10:4685-4689

Vaughn JP, Dijkwel PA, Hamlin JL (1990a) Replication initiates in a broad zone in the amplified CHO dihydrofolate reductase domain. Cell 61(6):1075-1087

Vaughn JP, Dijkwel PA, Mullenders LH, Hamlin JL (1990b) Replication Forks are associated with the nuclear matrix. Nucleic Acids Res 18(8):1965-1969

Von Meyenburg K, Hansen FG, Nielsen LD, Riise E (1978) Origin of replication oriC, of the $E$. coli chromosome on specialized transducing phages lambda-Asn. Mol Gen Genet 160:287-295

Wang S, Dijkwel PA, Hamlin JL (1998) Lagging-strand early-labelling, and two-dimensional gel assays suggest multiple potential initiation sites in the Chinese hamster dihydrofolate reductase origin. Mol Cell Biol 18:39-50

Wang L, Lin CM, Brooks S, Cimbora D, Groudine M, Aladjem MI (2004) The human beta-globin replication initiation region consists of two modular independent replicators. Mol Cell Biol 24(8):3373-3386

Yasuda S, Hirota Y (1977) Cloning and mapping of the replication origin of Escherichia coli. Proc Natl Acad Sci U S A 74:5458-5462 